\title{
Overview of MicroRNA Biogenesis, Mechanisms of Actions, and Circulation
}

OPEN ACCESS

Edited by:

Wei Ge,

University of Macau, Macau

Reviewed by:

Meisheng Yi,

Sun Yat-sen University, China

Toni R. Pak,

Loyola University Chicago,

United States

*Correspondence:

Chun Peng

cpeng@yorku.ca

Specialty section:

This article was submitted to

Experimental Endocrinology,

a section of the journal

Frontiers in Endocrinology

Received: 23 April 2018

Accepted: 28 June 2018

Published: 03 August 2018

Citation:

O'Brien J, Hayder H, Zayed Y and Peng C (2018) Overview of MicroRNA Biogenesis, Mechanisms of Actions,

and Circulation.

Front. Endocrinol. 9:402.

doi: 10.3389/fendo.2018.00402

\author{
Jacob O'Brien, Heyam Hayder, Yara Zayed and Chun Peng*
}

Department of Biology, York University, Toronto, ON, Canada

MicroRNAs (miRNAs) are a class of non-coding RNAs that play important roles in regulating gene expression. The majority of miRNAs are transcribed from DNA sequences into primary miRNAs and processed into precursor miRNAs, and finally mature miRNAs. In most cases, miRNAs interact with the $3^{\prime}$ untranslated region (3' UTR) of target mRNAs to induce mRNA degradation and translational repression. However, interaction of miRNAs with other regions, including the $5^{\prime}$ UTR, coding sequence, and gene promoters, have also been reported. Under certain conditions, miRNAs can also activate translation or regulate transcription. The interaction of miRNAs with their target genes is dynamic and dependent on many factors, such as subcellular location of miRNAs, the abundancy of miRNAs and target mRNAs, and the affinity of miRNA-mRNA interactions. miRNAs can be secreted into extracellular fluids and transported to target cells via vesicles, such as exosomes, or by binding to proteins, including Argonautes. Extracellular miRNAs function as chemical messengers to mediate cell-cell communication. In this review, we provide an update on canonical and non-canonical miRNA biogenesis pathways and various mechanisms underlying miRNA-mediated gene regulations. We also summarize the current knowledge of the dynamics of miRNA action and of the secretion, transfer, and uptake of extracellular miRNAs.

Keywords: microRNA biogenesis, gene regulation, microRNA dynamics, extracellular microRNA, cell-cell communication

\section{INTRODUCTION}

The discovery of the first microRNA (miRNA), lin-4, in 1993 by the Ambros and Ruvkun groups in Caenorhabditis elegans $(1,2)$ has revolutionized the field of molecular biology. Years before, lin-4 was characterized by the Horvitz's lab as one of the genes that regulate temporal development of $C$. elegans larvae $(3,4)$. Later in 1987, the same group found that a mutation in lin-4 had an opposite phenotype to a mutation in another gene, lin-14, yet a lin-14 suppressor mutation in a null-lin-4 line was wildtype $(5,6)$. Both Ambros and Ruvkun continued to study lin-4 and lin-14 after leaving the Horvitz's lab, only to discover later that lin-4 was not a protein-coding RNA but indeed a small noncoding RNA $(7,8)$. They also found that lin- 14 was post-transcriptionally downregulated through its $3^{\prime}$ untranslated region (UTR) and that lin-4 had a complementary sequence to that of the $3^{\prime}$ UTR of lin-14 (1). Therefore, they proposed that lin-4 regulates lin-14 at the post-transcriptional level (2). Since then, miRNAs have been detected in all animal model systems and some were shown to be highly conserved across species (9-12). New miRNAs are still being discovered (13) and their roles in gene regulation are well recognized. 
miRNAs are small non-coding RNAs, with an average 22 nucleotides in length. Most miRNAs are transcribed from DNA sequences into primary miRNAs (pri-miRNAs) and processed into precursor miRNAs (pre-miRNAs) and mature miRNAs. In most cases, miRNAs interact with the $3^{\prime}$ UTR of target mRNAs to suppress expression (14). However, interaction of miRNAs with other regions, including the $5^{\prime}$ UTR, coding sequence, and gene promoters, have also been reported (15). Furthermore, miRNAs have been shown to activate gene expression under certain conditions (16). Recent studies have suggested that miRNAs are shuttled between different subcellular compartments to control the rate of translation, and even transcription (17).

miRNAs are critical for normal animal development and are involved in a variety of biological processes (18). Aberrant expression of miRNAs is associated with many human diseases $(19,20)$. In addition, miRNAs are secreted into extracellular fluids. Extracellular miRNAs have been widely reported as potential biomarkers for a variety of diseases and they also serve as signaling molecules to mediate cell-cell communications (21-23). In this review, we have provided a brief overview of the different pathways of miRNA biogenesis in animals and the expanding complexity of their regulation of gene expression. Moreover, we have discussed the dynamics of miRNA intracellular localization and function. Finally, we have summarized the secretion and circulation of miRNAs and the potential roles of extracellular miRNAs in mediating intercellular communications.

\section{BIOGENESIS OF miRNAS}

miRNA biogenesis starts with the processing of RNA polymerase II/III transcripts post- or co-transcriptionally (14). About half of all currently identified miRNAs are intragenic and processed mostly from introns and relatively few exons of protein coding genes, while the remaining are intergenic, transcribed independently of a host gene and regulated by their own promoters $(13,24)$. Sometimes miRNAs are transcribed as one long transcript called clusters, which may have similar seed regions, and in which case they are considered a family (25). The biogenesis of miRNA is classified into canonical and noncanonical pathways (Figure 1).

\section{The Canonical Pathway of miRNA Biogenesis}

The canonical biogenesis pathway is the dominant pathway by which miRNAs are processed. In this pathway, pri-miRNAs are transcribed from their genes and then processed into premiRNAs by the microprocessor complex, consisting of an RNA binding protein DiGeorge Syndrome Critical Region 8 (DGCR8) and a ribonuclease III enzyme, Drosha (27). DGCR8 recognizes an N6-methyladenylated GGAC and other motifs within the primiRNA (28), while Drosha cleaves the pri-miRNA duplex at the base of the characteristic hairpin structure of pri-miRNA. This results in the formation of a $2 \mathrm{nt} 3^{\prime}$ overhang on pre-miRNA (29). Once pre-miRNAs are generated, they are exported to the cytoplasm by an exportin 5 (XPO5)/RanGTP complex and then processed by the RNase III endonuclease Dicer (27, 30). This processing involves the removal of the terminal loop, resulting in a mature miRNA duplex (31). The directionality of the miRNA strand determines the name of the mature miRNA form. The $5 \mathrm{p}$ strand arises from the $5^{\prime}$ end of the pre-miRNA hairpin while the $3 \mathrm{p}$ strand originates from the $3^{\prime}$ end. Both strands derived from the mature miRNA duplex can be loaded into the Argonaute (AGO) family of proteins (AGO1-4 in humans) in an ATP-dependent manner (32). For any given miRNA, the proportion of AGO-loaded $5 p$ or $3 p$ strand varies greatly depending on the cell type or cellular environment, ranging from near equal proportions to predominantly one or the other (33). The selection of the $5 p$ or $3 p$ strand is based in part on the thermodynamic stability at the $5^{\prime}$ ends of the miRNA duplex or a $5^{\prime} \mathrm{U}$ at nucleotide position 1 (34). Generally, the strand with lower $5^{\prime}$ stability or $5^{\prime}$ uracil is preferentially loaded into AGO, and is deemed the guide strand. The unloaded strand is called the passenger strand, which will be unwound from the guide strand through various mechanisms based on the degree of complementarity. The passenger strands of miRNA that contain no mismatches are cleaved by AGO2 and degraded by cellular machinery which can produce a strong strand bias. Otherwise, miRNA duplexes with central mismatches or non-AGO2 loaded miRNA are passively unwound and degraded (14).

\section{Non-canonical miRNA Biogenesis Pathways}

To date, multiple non-canonical miRNA biogenesis pathways have been elucidated (Figure 1). These pathways make use of different combinations of the proteins involved in the canonical pathway, mainly Drosha, Dicer, exportin 5, and AGO2. In general, the non-canonical miRNA biogenesis can be grouped into Drosha/DGCR8-independent and Dicer-independent pathways. Pre-miRNAs produced by the Drosha/DGCR8independent pathway resemble Dicer substrates. An example of such pre-miRNAs is mirtrons, which are produced from the introns of mRNA during splicing $(35,36)$. Another example is the 7-methylguanosine $\left(\mathrm{m}^{7} \mathrm{G}\right)$-capped pre-miRNA. These nascent RNAs are directly exported to the cytoplasm through exportin 1 without the need for Drosha cleavage. There is a strong $3 p$ strand bias most likely due to the $\mathrm{m}^{7} \mathrm{G}$ cap preventing $5 \mathrm{p}$ strand loading into Argonaute (37). On the other hand, Dicer-independent miRNAs are processed by Drosha from endogenous short hairpin RNA (shRNA) transcripts (38). These pre-miRNAs require AGO2 to complete their maturation within the cytoplasm because they are of insufficient length to be Dicer-substrates (38). This in turn promotes loading of the entire pre-miRNA into AGO2 and AGO2-dependent slicing of the $3 \mathrm{p}$ strand. The $3^{\prime}-5^{\prime}$ trimming of the $5 \mathrm{p}$ strand completes their maturation (39).

\section{MECHANISMS OF MIRNA-MEDIATED GENE REGULATION}

Most studies to date have shown that miRNAs bind to a specific sequence at the $3^{\prime}$ UTR of their target mRNAs to 


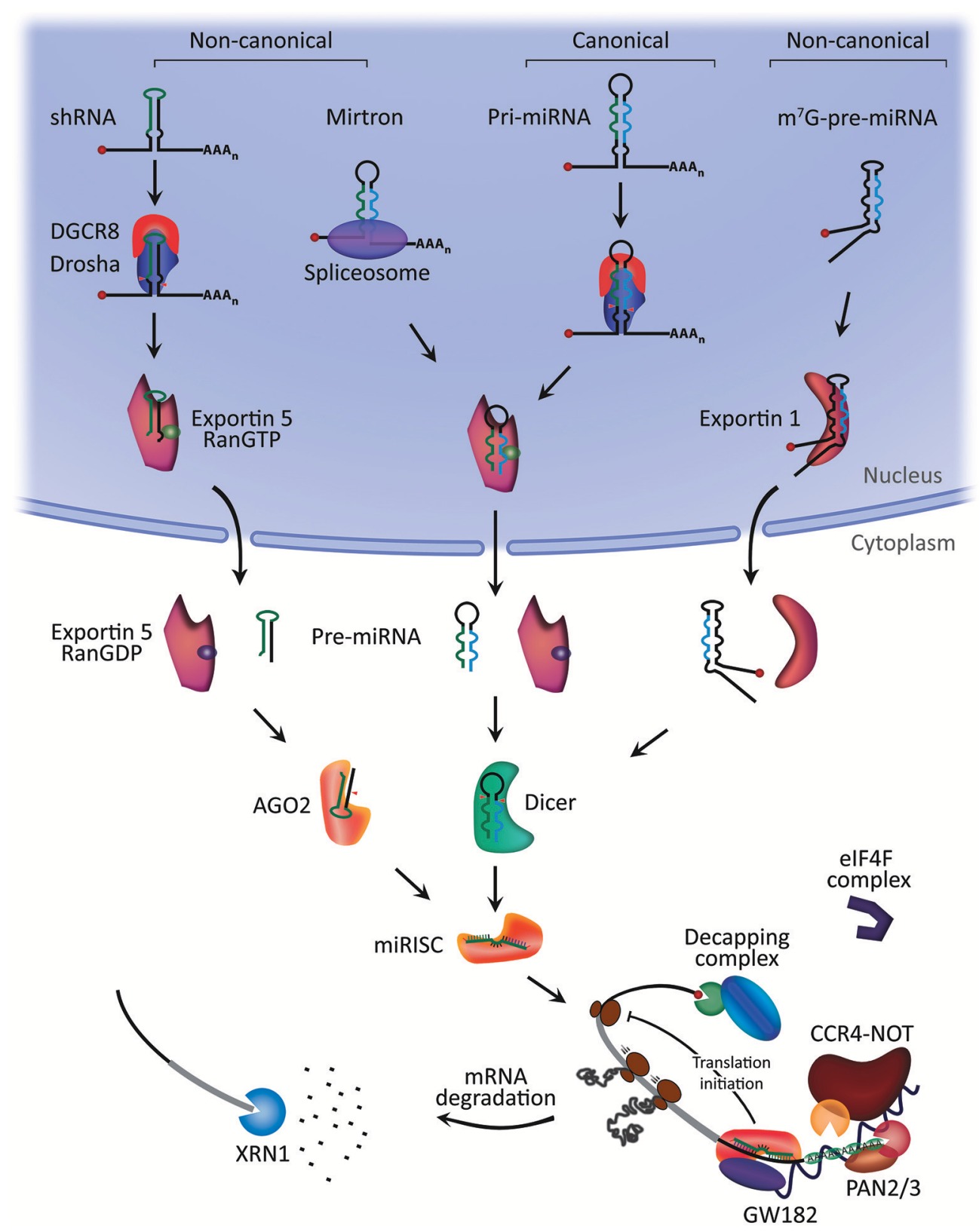

FIGURE 1 | MicroRNA biogenesis and mechanism of action. Canonical miRNA biogenesis begins with the generation of the pri-miRNA transcript. The microprocessor complex, comprised of Drosha and DiGeorge Syndrome Critical Region 8 (DGCR8), cleaves the pri-miRNA to produce the precursor-miRNA (pre-miRNA). The pre-miRNA is exported to the cytoplasm in an Exportin5/RanGTP-dependent manner and processed to produce the mature miRNA duplex. Finally, either the $5 p$ or $3 p$ strands of the mature miRNA duplex is loaded into the Argonaute (AGO) family of proteins to form a miRNA-induced silencing complex (miRISC). In the non-canonical pathways, small hairpin RNA (shRNA) are initially cleaved by the microprocessor complex and exported to the cytoplasm via Exportin5/RanGTP. They are further processed via AGO2-dependent, but Dicer-independent, cleavage. Mirtrons and 7-methylguanine capped ( $\left.\mathrm{m}^{7} \mathrm{G}\right)$-pre-miRNA are dependent on Dicer to complete their cytoplasmic maturation, but they differ in their nucleocytoplasmic shuttling. Mirtrons are exported via Exportin5/RanGTP while $m^{7} \mathrm{G}$-pre-miRNA are exported via Exportin1. All pathways ultimately lead to a functional miRISC complex. In most cases, miRISC binds to target mRNAs to induce translational inhibition, most likely by interfering with the elF4F complex. Next, GW182 family proteins bound to Argonaute recruit the poly(A)-deadenylases PAN2/3 and CCR4-NOT. PAN2/3 initiates deadenylation while the CCR4-NOT complex completes the process, leading to removal of the $\mathrm{m}^{7} \mathrm{G}$ cap on target mRNA by the decapping complex. Decapped mRNA may then undergo $5^{\prime}-3^{\prime}$ degradation via the exoribonuclease XRN1. Modified from Hayder et al. (26).

induce translational repression and mRNA deadenylation and decapping $(40,41)$. miRNA binding sites have also been detected in other mRNA regions including the $5^{\prime}$ UTR and coding sequence, as well as within promoter regions (42). The binding of miRNAs to $5^{\prime}$ UTR and coding regions have silencing effects on gene expression $(43,44)$ while miRNA interaction with promoter 
region has been reported to induce transcription (45). However, more studies are required to fully understand the functional significance of such mode of interaction.

\section{MicroRNA-Mediated Gene Silencing via MiRISC}

The minimal miRNA-induced silencing complex (miRISC) consists of the guide strand and AGO (46). The target specificity of miRISC is due to its interaction with complementary sequences on target mRNA, called miRNA response elements (MREs). The degree of MRE complementarity determines whether there is AGO2-dependent slicing of target mRNA or miRISC-mediated translational inhibition and target mRNA decay (47). A fully complementary miRNA:MRE interaction induces AGO2 endonuclease activity and targets mRNA cleavage (47). However, this interaction destabilizes the association between AGO and the $3^{\prime}$ end of the miRNA promoting its degradation $(48,49)$.

In animal cells, the majority of miRNA:MRE interactions are not fully complementary (50). Most MREs contain at least central mismatches to their guide miRNA, preventing AGO2 endonuclease activity. Consequently, AGO2 acts as a mediator of RNA interference, similar to the non-endonucleolytic AGO family members (AGO1, 3, and 4 in humans). In many cases, a functional miRNA:MRE interaction occurs via the 5' seed region (nucleotides 2-8) $(42,51)$. However, additional paring at the $3^{\prime}$ end aids in the stability and specificity of the miRNA-target interaction (15).

The formation of a silencing miRISC complex starts with the recruitment of the GW182 family of proteins by miRISC; GW182 provides the scaffolding needed to recruit other effector proteins (52), such as the poly(A)-deadenylase complexes PAN2-PAN3 and CCR4-NOT, following miRNA:target mRNA interaction (50, 53). Target mRNA poly(A)-deadenylation is initiated by PAN2/3 and completed by the CCR4-NOT complex. The interaction between the tryptophan (W)-repeats of GW182 and poly(A)-binding protein C (PABPC) promotes efficient deadenylation (50). Subsequently, decapping takes place facilitated by decapping protein 2 (DCP2) and associated proteins (52), followed by $5^{\prime}-3^{\prime}$ degradation by exoribonuclease 1 (XRN1) (54) (Figure 1).

\section{MicroRNA-Mediated Translational Activation}

Although most studies are focused on how miRNAs inhibit gene expression, some have also reported up-regulation of gene expression by miRNAs. In serum starved cells, AGO2 and another protein related to the miRNA-protein complex (microRNPs), Fragile-x-mental retardation related protein 1 (FXR1), were associated with AU-rich elements (AREs) at $3^{\prime}$ UTR to activate translation (55). Several miRNAs, including let7, were found to be associated with AGO2 and FXR1 to activate translation during cell cycle arrest, but they inhibit translation in proliferating cells (55). Upregulation of gene expression by miRNAs was also observed in quiescent cells, such as oocytes $(56,57)$. The miRNA-mediated activation of translation involves
AGO2 and FXR1 instead of GW182 (56). Other examples of gene activation by miRNAs include binding to the $5^{\prime}$ UTR of mRNAs encoding ribosomal proteins during amino acid starvation (58); thus suggesting that miRNA-mediated upregulation of gene expression occurs under specific conditions.

\section{MicroRNA-Mediated Transcriptional and Post-transcriptional Gene Regulation Within the Nucleus}

Through Importin-8 or Exportin-1, human AGO2 shuttles between the nucleus and cytoplasm via its interaction with TNRC6A (a GW182 family protein) which contains a nuclear localization and export signal (59). Nuclear localized miRISC was found to regulate both transcriptional rates and posttranscriptional levels of mRNA (59-61) and associate with euchromatin at gene loci with active transcription (62). However, our understanding of when and how miRNAs exert their functions in the nucleus is still limited.

It has been reported that low molecular weight miRISC can interact with mRNAs within the nucleus and induce nuclear mRNA degradation, although the mechanism behind this is unclear $(59,61,63)$. Enrichment of miRNA at actively transcribed genes may suggest that miRISC interacts with target mRNA co-/post-transcriptionally. The involvement of AGO and Drosha in mRNA splicing $(64,65)$ further supports cotranscriptional miRISC:mRNA interactions. miRISC may also regulate transcription directly. A study showed that AGO2 was concentrated in the nucleus of senesced fibroblasts and interacted with miRISC and retinoblastoma $(\mathrm{Rb})$ to suppress the transcription of proliferation-promoting genes regulated by $\mathrm{Rb} / \mathrm{E} 2 \mathrm{~F}$. It was noted that let-7f was bound to MREs found in the promoters of two E2F target genes, CDCA 8 and $C D C 2$, in an AGO2-dependent manner (60). Also, a subset of AGO-promoter bound genes was upregulated following senescence, and AGO2 was found to co-immunoprecipitate with euchromatin (60). A more recent study by Miao et al. (66) found nuclear miR522 interacting with a DNA cruciform structure (a stem-loop on sense and antisense DNA strands) within the promoter of CYP2E1 and suppressing its transcription (66). miRNAs have also been shown to interact at genomic loci, where enhancer-derived RNA (eRNA) are transcribed, and increase mRNA levels of adjacent genes by promoting a transcriptionally active chromatin state (67) while altering alternative splicing profiles (64). The overall role of miRISC in the regulation of chromatin state and structure and transcriptional control remain to be determined, but these current data suggest a transcription factor-like role. It is also possible that miRISC may be involved in the establishment of de novo methylation, and by extension, the compactification of chromatin into nuclear compartments, and mediation of genomic remodeling.

\section{DYNAMICS OF MIRNA ACTIONS}

Studies have revealed that miRNA-mediated gene regulation is dynamic and helps to buffer gene expression to a steady state. It is only recently that a more comprehensive understanding of 
miRNA dynamics has begun to shed light on the highly robust nature of miRNA-mediated gene regulation. Factors that may contribute to the robustness of miRNA-mediated gene regulation include the functionalized compartmentalization and shuttling of miRISC within the cells. The availability and abundancy of miRNAs and their target mRNAs are also contributing factors in determining which genes are regulated. Although this is not always the case, miRNA suppression of mRNA targets is not ubiquitous between cell types. Alternative splicing and alternative polyadenylation affecting $3^{\prime}$ UTRs, and cell type-specific RNA binding proteins that affect target mRNA secondary structures, change the available pool of MREs $(63,68,69)$. This renders subsets of mRNAs sensitive or insensitive to miRNA-mediated gene regulation in a cell type/state-specific manner.

\section{Subcellular Compartmentalization of miRNAs}

miRISC and target mRNA have been observed to localize in multiple subcellular compartments including rough endoplasmic reticulum (rER) (70), processing (P)-bodies (71), stress granules (SG) (72), the trans-Golgi network (TGN), early/late endosomes (73), multivesicular bodies (MVB) (74), lysosomes (74), mitochondria $(75,76)$, and the nucleus $(66,77)$ (Figure 2). With regards to miRNA activity, the result is that components that facilitate miRNA post-transcriptional gene regulation are enriched at sites where miRISC:mRNA complexes localize. This in effect acts to spatially enrich mRNA and miRISC concentrations over time and promote efficient regulation of gene expression (70).

P-bodies were identified early on as possible sites involved with miRNA-mediated suppressive activity (78). They are cytoplasmic foci depleted of ribosomes (79) and enriched with enzymatic mRNA degradation machinery, such as mRNA decapping proteins, the CCR4-NOT complex, XRN1, and GW182 family proteins (78). Furthermore, P-bodies form in an RNA-dependent manner as a consequence of RNAi and RNA degradation (80). Recently, P-bodies with active miRISC have been associated with SYNE1 (nesprin-1) which acts to adhere Argonaute and other P-body components to microtubules (81). Disruption of nesprin-1 activity through mutations and RNAi significantly decreased miRNA suppression of target mRNA and P-body formation. On the other hand, stabilization of microtubules with Taxol led to translation inhibition but not mRNA decay of HIF1A following accumulation in P-bodies (82). Importantly, P-body accumulation was miRISC-dependent and reversible as recovery after Taxol treatment led to P-body dissociation back to control levels and HIF1A polysome reassociation. It is not clear why a microtubule stabilization would lead to an increase in P-body count. The reduced polysome occupancy of HIF1A observed by Carbonaro et al. (82) may lead to a buildup of HIF1A mRNA on the static microtubule network promoting an increase in HIF1A-bound miRISC. This in turn may enrich miRISC on the static microtubule network and nucleate P-body formation. Typical microtubule instability may in effect dilute microtubule-associated miRISC by preventing enrichment at sites of nucleation. However, the degree to which
P-bodies are necessary for efficient miRNA-mediated suppression is uncertain as mRNA degradation machinery exists diffusely throughout the cytoplasm, and at other subcellular locations, and can confer RNAi activities even in the absence of P-bodies (78).

Polysomes, which are complexes of mRNA with multiple translating ribosomes, are generally found freely within the cytoplasm or bound to the cytoskeleton or membranous subcellular organelles, such as rER. miRISC has also been found to copurify with polysomes, and the miRISC:mRNA complexes bound to these polysomes were associated with increased levels of translational inhibition and mRNA degradation (83). A recent study showed that miRNAs, AGO2, and target mRNAs are associated with rER-membrane-bound polysomes, and this occurs before miRNA-mediated translational repression (70). Further work by the same group has led to the finding that rER-bound mRNA, destined for miRNA-dependent degradation, complete this process within endosomes and MVBs followed by miRISC recycling back into the cytoplasm (73). Importantly, this interaction is miRNA-dependent; disruption of translation, micrococcal nuclease degradation of cytoplasmic mRNA, or mRNA mutants lacking cognate MRE led to a loss of polysome/miRISC copurification $(70,84)$. Additionally, the degree of polysome occupancy of target mRNAs is dependent on the affinity between miRNA seed region and MRE, but not on miRNA abundance (84). Moreover, at any given time the average proportion of polysome-bound and -unbound miRISC, called the polysome occupancy, was below $40 \%$. These data are in agreement with high rates of miRNA-bound AGO sampling of targets observed in vitro (85), i.e., miRISC is able to probe for MREs quickly, but does not form stable interactions on its own. Together these data elude to a key aspect of miRNA functioning; there is a crucial equilibrium between MRE bound and unbound states and this equilibrium is important for the spatiotemporal dynamics of miRISC. This allows for miRNA to respond quickly to changes in subcellular environments and dynamically regulate many target mRNAs.

\section{A Global View of miRNA at the Cellular Level}

The interplay between miRNA abundance/localization, cell type, cell state, and miRNA-mediated regulation is still under intense investigation. Recently, the work by the Functional Annotation of the Mammalian Genome (FANTOM5) consortium found that for any given human cell type, the top five expressed miRNAs represent on average $\sim 50 \%$ of the overall miRNA pool (13). Moreover, approximately half of the expressed miRNAs are cell type enriched, one quarter are broadly expressed, and the remaining had low-level expression regardless of cell type. These data help fortify the general roles that miRNA play within cells. Generally, miRNA can regulate gene networks dynamically and/or transiently, e.g., feedback and feedforward loops (86), and steady state gene regulation, e.g., upregulation of a miRNA throughout differentiation (87). In both cases, higherorder effects on gene regulatory networks can propagate (88), such as regulation of transcription factor expression leading to changes in transcriptional profiles. Intriguingly, miRNA do not 


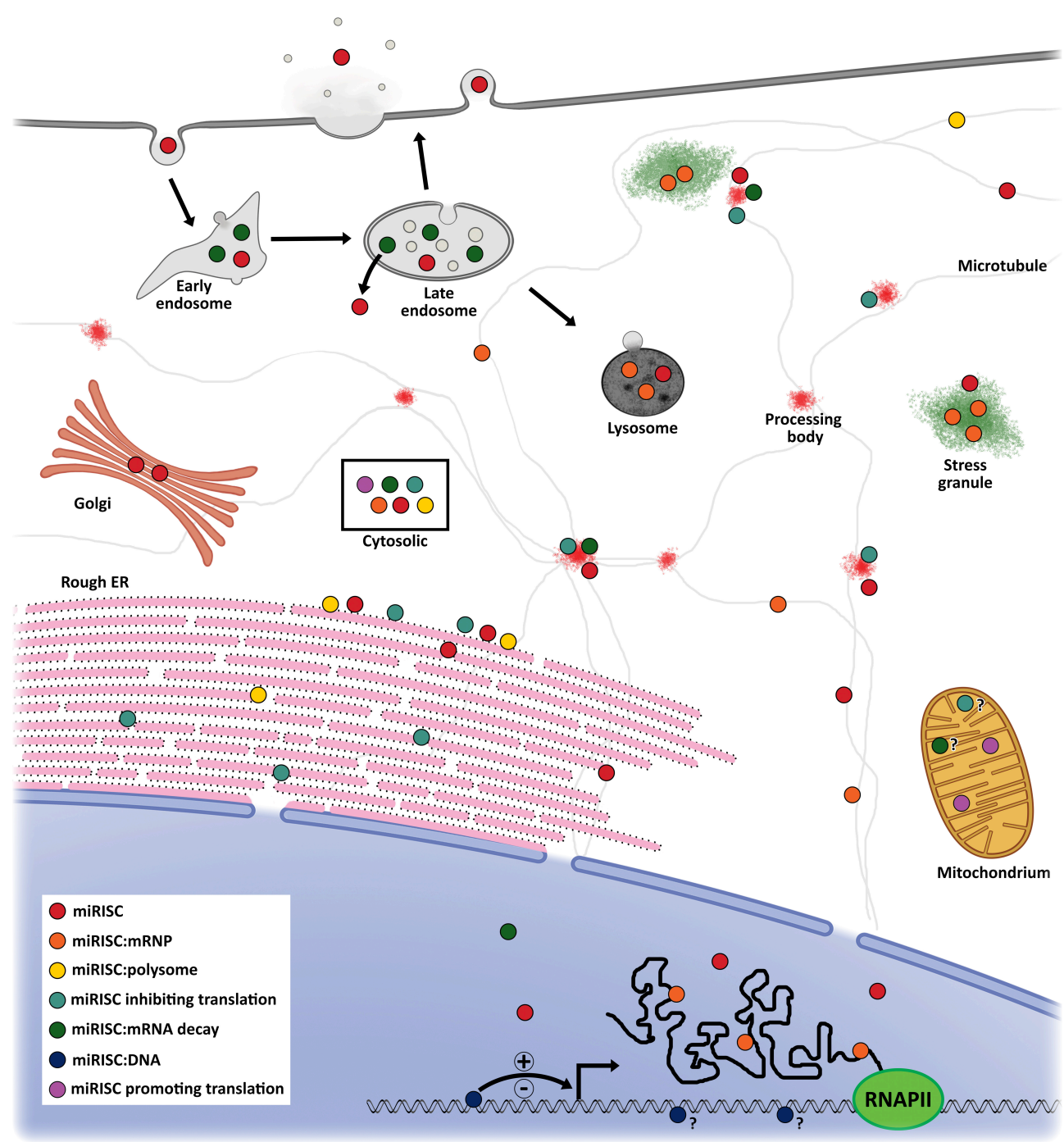

FIGURE 2 | Proposed model of miRNA localization and function. miRISC has been detected in several subcellular locations. In the nucleus, miRISC is enriched at sites of active transcription where it can interact with DNA to promote active or inactive chromatin states. It can also interact with nascent mRNA to promote more efficient splicing or alternate splicing profiles. miRISC can interact with nuclear messenger ribonucleoprotein (mRNP) to promote its degradation or remain in A miRISC:mRNP complex as it is shuttled out of the nucleus. Cytoplasmic miRISC can diffuse throughout the cytosol or undergo shuttling, most likely via microtubules. Within the cytosol, miRISC can associate with polysomes, inhibit translation initiation, mediate mRNA decay, or promote translational activation. On the rough endoplasmic reticulum, miRISC can interact with translating mRNA to inhibit translation. Furthermore, unbound miRISC can also accumulate on the rER to interact with newly rER-bound mRNA. Rough ER miRISC:mRNP complexes that are translationally inhibited can shuttle to the early/late endosomes to complete mRNA deadenylation and decay. miRISC can then be recycled into the cytosol or shuttled to the lysosome for degradation. miRISC may also localize to transient, membrane-free processing bodies where it can mediate target mRNA translational inhibition and storage or decay. Under certain cellular conditions, miRISC:mRNPs may be shuttled to stress granules for storage and/or degradation. miRISC can also localize to the mitochondria to promote translational activation or mRNA translational inhibition and decay. Localization of miRISC within the Golgi is likely from vesicles secreted from the early endosome. Moreover, endocytosed miRISC may be shuttled to the Golgi or recycled into the cytosol. Lastly, vesicular or vesicle-free miRISC can be exocytosed from at least the late endosome into the extracellular milieu to mediate cell-cell communication.

solely, or maybe even predominantly, function as target-specific regulators but may play key roles in the post-transcriptional reduction of expression noise $(89,90)$. In this way miRNA promote stable gene expression by buffering out stochastic fluctuations in transcription. A common indicator of expression noise control is high mRNA to protein ratios, rendering reduced translational rates resistant to random fluctuations in mRNA concentration (91), i.e., a small change to a highly abundant mRNA has little effect on protein output. This behavior is seen throughout the animal and bacterial kingdoms, selecting for controlled protein output rather than coupling of mRNA/protein levels (92). Accordingly, the strongest predictor of protein level 
for any given gene is the rate of translation, followed by mRNA levels (93).

An important concept in connecting miRNA dynamics and cellular gene expression networks is the idea of MRE load (94). There is an MRE load for each miRNA which represents the total number of available binding sites on all targetable RNA molecules within a cell. Simply put, a miRNA may interact with or sample all available MREs, but the retention time will be longer for higher affinity MREs compared to lower affinity MREs (94). This has the effect of diluting cellular miRNAs amongst many potential targets such that only a small proportion of each target mRNA is bound to a cognate miRNA at any given time (94). On the other hand, mRNAs with higher affinity MREs generally show greater sensitivity to miRNA-mediated posttranscriptional repression $(84,94)$. Nevertheless, the balance between MRE load and cognate miRNA abundance can lead to varying effects. Increasing the MRE load of a single miRNA, by upregulating one gene, has the effect of sequestering that miRNA away from other targets $(94,95)$. In this way, modulation of MRE load with competing endogenous RNAs (ceRNAs), such as with circular RNAs (circRNAs) (96), can act to sequester miRISC from target mRNA, leading to derepression of target mRNA (97). To complicate matters further, by altering subcellular localizations of miRISC, the MRE load can be modulated. At sites of synaptic formation in neurons, rapid and highly specific RNAi takes place due to the colocalization of target mRNAs and cognate miRNAs (98).

An individual mRNA may contain many MREs (99), and thus contributes to multiple MRE loads for different miRNA. Although to some degree, each individual mRNA with multiple MREs may act as a ceRNA, multiple MREs can also act to increase miRISC occupancy. Cooperation of multiple, proximal MREs on target mRNA has been shown to increase RNAi activity and increase retention times of miRISC complexes on those mRNA, most likely through the three AGO binding sites on the GW182 family proteins $(94,100)$. In this way, low expression but functional miRNA may synergistically increase RNAi activity on a subset of target mRNAs, thereby effectively enhancing the concentration of cognate miRNAs for specific mRNAs $(101,102)$. Inversely, low miRNA levels can be compensated for, when target mRNA levels are high, by stimulating increased loading of cognate miRNA into AGO, thereby improving RNAi activity (103). Synergistic effects of miRNAs have been shown to be important for biological processes, such as neurogenesis (104) and human embryonic stem cell pluripotency and differentiation (105). Highly synergistic miRNA regulation of target mRNA may also have implications in diseases, such as oncogenesis. For example, cyclin-dependent kinase inhibitor 1A (CDKN1A), a tumor suppressor that is downregulated in multiple cancers (106), is targeted by at least 28 miRNAs and many of which are upregulated together in cancers where CDKN1A has been implicated (107). This may suggest that the upregulation of sets of miRNAs in these cancers can synergistically downregulate CDKN1A. miRNA synergism has also been exploited as a therapeutic strategy (108).

In addition to specific miRNA/mRNA dynamics, changes in global miRISC localization in response to changes in cellular environments, such as stress or serum starvation (109), also affect miRNA activity. In a study by Wang et al. (110), upon serum starvation of multiple human cell lines, there was an immediate exportation of stable, vesicular or vesicle-free miRNA and a concomitant decrease of intracellular miRNA levels (110). Both cell stress induced by heat shock and translation inhibition following treatment with hippuristanol or cycloheximide induced translocation of miRISC from the nucleus and cytoplasm to transient, cytoplasmic SG $(72,111)$. SG are known to act as intermediate storage of messenger ribonucleoproteins (mRNPs) that have stalled during translation or following viral infection (112). SG components can also return to the cytoplasm, exchange with P-bodies, or be digested by lysosomes $(81,112)$. miRISC that is localized to SG following cell stress also contained target mRNAs, leading to a reduction of RNAi activity. The extracellular release of miRNA upon cell stress and localization of miRNA:mRNA complexes to SG suggests an mRNA-protective role.

\section{CIRCULATION OF MIRNAs}

Numerous studies have demonstrated that miRNAs can be released into extracellular fluids. Extracellular miRNAs can be used as biomarkers for a variety of diseases. These studies have been extensively reviewed (113-115) and therefore will not be discussed here. The extracellular miRNAs can be delivered to target cells and they may act as autocrine, paracrine, and/or endocrine regulators to modulate cellular activities (116). In this regard, miRNAs have hormone-like activities.

\section{MicroRNAs in Biological Fluids}

Many studies have detected extracellular/circulating miRNAs in biological fluids, such as plasma and serum $(117,118)$, cerebrospinal fluid (119), saliva (120), breast milk (121), urine, tears, colostrum, peritoneal fluid, bronchial lavage, seminal fluid (122), and ovarian follicular fluid (123). Contrary to cellular RNA species, extracellular miRNAs are highly stable, resisting degradation at room temperature for up to 4 days and in deleterious conditions such as boiling, multiple freeze-thaw cycles, and high or low $\mathrm{pH}(117,124)$.

Two populations of extracellular miRNAs exist in biological fluids. One can be found in vesicles such as exosomes, microvesicles, and apoptotic bodies $(116,120)$ while the other is associated with proteins, especially AGO2 (120, 125). There have been some discrepancies on the relative abundancies of these two populations. While several studies found that the majority of extracellular miRNAs are not associated with exosomes/microvesicles but are instead bound to AGO2 (118, 125), another study reported that extracellular miRNAs are present predominantly in exosomes in human serum and saliva (120). Since these studies only measured a selected group of miRNAs in a few plasma samples, it is possible that the existence of predominantly exosomal or vesicle-free miRNAs is dependent on the miRNA itself, the cell type they originate from, and/or other factors affecting the secretion of miRNAs in individuals. Other proteins found to bind extracellular miRNAs include high-density lipoprotein (HDL) $(126,127)$ and nucleophosmin 
1 (NPM1) (110, 118, 128). The presence of miRNAs in vesicles or with accompanying proteins is generally thought to protect extracellular miRNAs and increase their stability in the extracellular milieu (120).

\section{Secretion and Uptake of microRNAs}

Although some extracellular miRNAs are regarded as byproducts of cellular activities, such as cell injury or death (128), increasing evidence suggests that the release of extracellular miRNAs is a regulated process. It has been shown that the secretion of exosomal miRNAs is mediated by a ceramidedependent pathway and the secreted miRNAs exert growth regulatory effects in target cells (129). Recently, it was demonstrated that atheroprotective laminar shear stress induced the release of vesicle-free miR-126-3p and other miRNAs, as well as AGO2, from endothelial cells by activating vesicle-associated membrane protein 3 (VAMP3) and synaptosomal-associated protein 23 (SNAP23) (130). This study also showed that miRNAs secreted from endothelium can regulate the activity of smooth muscle cells (130). In neuroendocrine cells, miRNAs in large dense-core vesicles (LDCVs) are released by exocytosis through vesicle fusion, and this process is mediated by the SNARE complex and accelerated by $\mathrm{Ca}^{2+}$ stimulus (131). Secretion of miRNAs via exosomes have also been reported to be regulated by signaling molecules, such as interleukin-4 (IL4) (132) and Docosahexaenoic acid (DHA) (133). IL4-activated macrophages were found to secrete exosomes carrying oncogenic miRNAs to promote invasiveness of breast cancer cells (132). On the other hand, DHA, which has anticancer and anti-angiogenic activities, induced the secretion of miRNA-containing exosomes that exert inhibitory effects on tumor angiogenesis (133).

Many studies have also demonstrated that extracellular miRNAs can exert biological functions in recipient cells to regulate their activity, thereby acting as intercellular signaling molecules. For example, exosome mediated transfer of miR-105 from metastatic breast cancer cells to endothelial cells directly targeted a tight junction protein, zonula occludens 1 (ZO-1), and this led to the destruction of the barrier function of endothelium and promoted metastasis (134). Moreover, exosomes from umbilical cord blood were found to be enriched in miR-21-3p, which promoted the proliferation and migration of fibroblasts, and induced the angiogenic activities of endothelial cells, leading to accelerated wound healing (135). miRNAs, specifically miR$342-3 p$ and miR-1246, secreted from a highly metastatic human oral cancer cell line, were found to induce metastasis in a poorly metastatic cancer cell line (136). Extracellular miRNAs have also been reported to bind to Toll-like receptors (137), activate downstream signaling events, and eventually lead to biological responses, such as tumor growth and metastasis (138), and neurodegeneration (139). Thus, miRNAs may act as chemical messengers to regulate cell-cell communications.

The mechanisms of extracellular miRNA uptake are not well understood. It has been proposed that vesicleassociated extracellular miRNAs may enter cells by endocytosis, phagocytosis, or direct fusion with the plasma membranes, while vesicle-free secreted miRNAs may be taken up by specific receptors on the cell surface (140). Indeed, several studies have shown that miRNAs enter recipient cells by endocytosis and micropinocytosis $(141,142)$. This process has been reported to be dependent on clathrin, but not on caveolae or lipid rafts in PC12 cells (142). However, another study conducted in A549-P cells showed that endocytosis of exosomal miRNAs is mediated by caveolae- and lipid raft-dependent pathways (143). Furthermore, vesicle-free miRNAs associated with HDL are taken up by HDL receptor and scavenger receptor BI (SR-BI) receptor in the plasma membrane of the target cells $(126,127)$. miRNAs have also been shown to transfer between co-cultured cells via direct cell-cell contact and gap junctions (144). While these studies suggest that extracellular miRNAs can interact with recipient cells via multiple mechanisms, the factors that determine the specificity of such interactions need to be investigated.

\section{CONCLUDING REMARKS}

Since the discovery of miRNAs in the earlier 1990s, tremendous progress has been made on how miRNAs are produced within cells, how they exert regulatory effects on gene expression, and how they are involved in various physiological and pathological events. It is now clear that miRNAs are powerful gene regulators, and that they not only help control mRNA stability and translation but are also involved in transcription. However, our understanding of when and how miRNAs can exert regulatory effects on transcription is limited. Similarly, the conditions under which miRNAs elicit translational activation need to be further explored. In addition, careful analysis and consideration of experimental techniques and model systems should be employed when attempting to generalize miRNA capabilities. The assaying of miRNA activity within a test tube may not be recapitulated within the cellular environment and thus should be viewed with caution. Many studies have been conducted in vitro by transfecting pre-miRNAs or mature mRNA mimics into immortalized and cancer cell lines. The extent to which findings from such studies reflect the endogenous miRNA functions in vivo requires further study. Also, the addition of chemical tags to miRNA could also impact miRNA:MRE interaction or AGO:miRNA interactions, specifically with $5^{\prime}$ and $3^{\prime}$ miRNA nucleotide modifications. The first and last miRNA nucleotides clamp the miRNA within AGO proteins, and thus tags to these regions may affect miRNA functioning in unpredictable ways.

Recent studies have shed light on the dynamic nature of miRNA actions and further revealed the complexity of miRNA-mediated gene regulation. Many factors contribute to the activity of miRNAs, including subcellular location, miRNA/mRNA abundance, miRNA:MRE affinity, cell type/state, and the availability of various miRISC components. miRNAs in the nucleus play a role in regulating transcription and alternative splicing. Cytosolic miRISC components shuttle between different compartments. Moreover, their localization, together with the levels of miRNAs and target mRNAs, and the affinity of the miRNA-mRNA interaction, are important for efficient gene regulation. Recent advances in single molecule imaging will greatly impact the field, as has already begun. Viewing the movement of single miRNA and/or mRNA with high spatial 
and temporal resolution will help us understand this complex dynamic in an unprecedented way. Investigation of large scale, global miRNA interactomes will also propel the field forward, allowing powerful mathematical models to be applied to highly complex regulatory networks.

It is now accepted that extracellular/circulating miRNAs can not only serve as biomarkers for diseases, but also play important roles in intercellular communication. miRNAs regulate the activity of host cells, and they are also secreted and transferred to recipient cells. Many studies have shown that extracellular miRNAs are functionally active in recipient cells. Some miRNAs can even interact with cell surface receptors, such as Tolllike receptors. Therefore, miRNAs have hormone-like activities. However, most studies conducted so far were done in vitro using co-culture of different cell types. More in vivo studies are required to determine whether miRNAs target specific cells under physiological conditions. Although miRceptors have been

\section{REFERENCES}

1. Lee RC, Feinbaum RL, Ambros V. The C. elegans heterochronic gene lin-4 encodes small RNAs with antisense complementarity to lin-14. Cell (1993) 75:843-54. doi: 10.1016/0092-8674(93)90529-Y

2. Wightman B, Ha I, Ruvkun G. Posttranscriptional regulation of the heterochronic gene lin-14 by lin- 4 mediates temporal pattern formation in C. elegans. Cell (1993) 75:855-62. doi: 10.1016/0092-8674(93)90530-4

3. Horvitz HR, Sulston JE. Isolation and genetic characterization of cell-lineage mutants of the nematode Caenorhabditis elegans. Genetics (1980) 96:435-54.

4. Chalfie M, Horvitz HR, Sulston JE. Mutations that lead to reiterations in the cell lineages of C. Elegans. Cell (1981) 24:59-69. doi: 10.1016/0092-8674(81)90501-8

5. Ambros V, Horvitz HR. The lin-14 locus of Caenorhabditis elegans controls the time of expression of specific postembryonic developmental events. Genes Dev. (1987) 1:398-414. doi: 10.1101/gad.1.4.398

6. Ferguson EL, Sternberg PW, Horvitz HR. A genetic pathway for the specification of the vulval cell lineages of Caenorhabditis elegans. Nature (1987) 326:259-67.

7. Lee R, Feinbaum R, Ambros V. A short history of a short RNA. Cell (2004) 116(2 Suppl.), S89-92. doi: 10.1016/S0092-8674(04)00035-2

8. Almeida MI, Reis RM, Calin GA. MicroRNA history: discovery, recent applications, and next frontiers. Mutat Res. (2011) 717:1-8. doi: 10.1016/j.mrfmmm.2011.03.009

9. Pasquinelli AE, Reinhart BJ, Slack F, Martindale MQ, Kuroda MI, Maller B, et al. Conservation of the sequence and temporal expression of let-7 heterochronic regulatory RNA. Nature (2000) 408:86-9. doi: 10.1038/35040556

10. Davis-Dusenbery BN, Hata A. Mechanisms of control of microRNA biogenesis. J Biochem. (2010) 148:381-92. doi: 10.1093/jb/mvq096

11. Li SC, Chan WC, Hu LY, Lai CH, Hsu CN, Lin WC. Identification of homologous microRNAs in 56 animal genomes. Genomics (2010) 96:1-9. doi: 10.1016/j.ygeno.2010.03.009

12. Friedlander MR, Lizano E, Houben AJ, Bezdan D, Banez-Coronel M, Kudla $\mathrm{G}$, et al. Evidence for the biogenesis of more than 1,000 novel human microRNAs. Genome Biol. (2014) 15:R57. doi: 10.1186/gb-2014-15-4-r57

13. de Rie D, Abugessaisa I, Alam T, Arner E, Arner P, Ashoor H, et al. An integrated expression atlas of miRNAs and their promoters in human and mouse. Nat Biotechnol. (2017) 35:872-8. doi: 10.1038/nbt.3947

14. Ha M, Kim VN. Regulation of microRNA biogenesis. Nat Rev Mol Cell Biol. (2014) 15:509-24. doi: 10.1038/nrm3838

15. Broughton JP, Lovci MT, Huang JL, Yeo GW, Pasquinelli AE. Pairing beyond the Seed Supports MicroRNA Targeting Specificity. Mol Cell. (2016) 64:32033. doi: 10.1016/j.molcel.2016.09.004 proposed (137), apart from the Toll-like receptors, they remain to be identified. Mechanisms by which miRNAs are secreted and taken up by cells are not well understood and require further investigation.

\section{AUTHOR CONTRIBUTIONS}

All authors listed have made a substantial, direct and intellectual contribution to the work, and approved it for publication.

\section{FUNDING}

Work in our laboratory was supported by grants from the Canadian Institutes of Health Research (MOP-81370, CCI92222, CCI-132565, MOP-89931, and PJT-153146) and Natural Science and Engineering Research Council to CP. JO and HH were supported by the Ontario Graduate Scholarship.

16. Vasudevan S. Posttranscriptional upregulation by microRNAs. Wiley Interdiscip Rev RNA (2012) 3:311-30. doi: 10.1002/wrna.121

17. Makarova JA, Shkurnikov MU, Wicklein D, Lange T, Samatov TR, Turchinovich AA, et al. Intracellular and extracellular microRNA: an update on localization and biological role. Prog Histochem Cytochem. (2016) 51:3349. doi: 10.1016/j.proghi.2016.06.001

18. Fu G, Brkic J, Hayder H, Peng C. MicroRNAs in human placental development and pregnancy complications. Int J Mol Sci. (2013) 14:5519-44. doi: 10.3390/ijms14035519

19. Tufekci KU, Oner MG, Meuwissen RL, Genc S. The role of microRNAs in human diseases. Methods Mol Biol. (2014) 1107:33-50. doi: 10.1007/978-1-62703-748-8_3

20. Paul P, Chakraborty A, Sarkar D, Langthasa M, Rahman M, Bari M, et al. Interplay between miRNAs and human diseases. J Cell Physiol. (2018) 233:2007-18. doi: 10.1002/jcp.25854

21. Hayes J, Peruzzi PP, Lawler S. MicroRNAs in cancer: biomarkers, functions and therapy. Trends Mol Med. (2014) 20:460-9. doi: 10.1016/j.molmed.2014.06.005

22. Wang J, Chen J, Sen S. MicroRNA as Biomarkers and Diagnostics. J Cell Physiol. (2016) 231:25-30. doi: 10.1002/jcp.25056

23. Huang W. MicroRNAs: biomarkers, diagnostics, and therapeutics. Methods Mol Biol. (2017) 1617:57-67. doi: 10.1007/978-1-4939-7046-9_4

24. Kim YK, Kim VN. Processing of intronic microRNAs. EMBO J. (2007) 26:775-83. doi: 10.1038/sj.emboj.7601512

25. Tanzer A, Stadler PF. Molecular evolution of a microRNA cluster. J Mol Biol. (2004) 339:327-35. doi: 10.1016/j.jmb.2004.03.065

26. Hayder H, O’Brien J, Nadeem U, Peng C. MicroRNAs: crucial regulators of placental development. Reproduction (2018) 155:R259-71. doi: 10.1530/REP-17-0603

27. Denli AM, Tops BB, Plasterk RH, Ketting RF, Hannon GJ. Processing of primary microRNAs by the Microprocessor complex. Nature (2004) 432:231-5. doi: 10.1038/nature03049

28. Alarcon CR, Lee H, Goodarzi H, Halberg N, Tavazoie SF. N6methyladenosine marks primary microRNAs for processing. Nature (2015) 519:482-5. doi: 10.1038/nature14281

29. Han J, Lee Y, Yeom KH, Kim YK, Jin H, Kim VN. The Drosha-DGCR8 complex in primary microRNA processing. Genes Dev. (2004) 18:3016-27. doi: $10.1101 / \operatorname{gad} .1262504$

30. Okada C, Yamashita E, Lee SJ, Shibata S, Katahira J, Nakagawa A, et al. A high-resolution structure of the pre-microRNA nuclear export machinery. Science (2009) 326:1275-9. doi: 10.1126/science.1178705

31. Zhang H, Kolb FA, Jaskiewicz L, Westhof E, Filipowicz W. Single processing center models for human Dicer and bacterial RNase III. Cell (2004) 118:5768. doi: 10.1016/j.cell.2004.06.017 
32. Yoda M, Kawamata T, Paroo Z, Ye X, Iwasaki S, Liu Q, et al. ATP-dependent human RISC assembly pathways. Nat Struct Mol Biol. (2010) 17:17-23. doi: $10.1038 / \mathrm{nsmb} .1733$

33. Meijer HA, Smith EM, Bushell M. Regulation of miRNA strand selection: follow the leader? Biochem Soc Trans. (2014) 42:1135-40. doi: 10.1042/BST20140142

34. Khvorova A, Reynolds A, Jayasena SD. Functional siRNAs and miRNAs exhibit strand bias. Cell (2003) 115:209-16. doi: 10.1016/S0092-8674(03)00801-8

35. Ruby JG, Jan $\mathrm{CH}$, Bartel DP. Intronic microRNA precursors that bypass Drosha processing. Nature (2007) 448:83-6. doi: 10.1038/nature05983

36. Babiarz JE, Ruby JG, Wang Y, Bartel DP, Blelloch R. Mouse ES cells express endogenous shRNAs, siRNAs, and other Microprocessorindependent, Dicer-dependent small RNAs. Genes Dev. (2008) 22:2773-85. doi: 10.1101/gad.1705308

37. Xie M, Li M, Vilborg A, Lee N, Shu MD, Yartseva V, et al. Mammalian $5^{\prime}$ capped microRNA precursors that generate a single microRNA. Cell (2013) 155:1568-80. doi: 10.1016/j.cell.2013.11.027

38. Yang JS, Maurin T, Robine N, Rasmussen KD, Jeffrey KL, Chandwani R, et al. Conserved vertebrate mir-451 provides a platform for Dicer-independent, Ago2-mediated microRNA biogenesis. Proc Natl Acad Sci USA. (2010) 107:15163-8. doi: 10.1073/pnas.1006432107

39. Cheloufi S, Dos Santos CO, Chong MMW, Hannon GJ. A dicer-independent miRNA biogenesis pathway that requires Ago catalysis. Nature (2010) 465:584-9. doi: 10.1038/nature09092

40. Huntzinger E, Izaurralde E. Gene silencing by microRNAs: contributions of translational repression and mRNA decay. Nat Rev Genet. (2011) 12:99-110. doi: $10.1038 / \mathrm{nrg} 2936$

41. Ipsaro JJ, Joshua-Tor L. From guide to target: molecular insights into eukaryotic RNA-interference machinery. Nat Struct Mol Biol. (2015) 22:20-8. doi: 10.1038/nsmb.2931

42. $\mathrm{Xu} \mathrm{W,} \mathrm{San} \mathrm{Lucas} \mathrm{A,} \mathrm{Wang} \mathrm{Z,} \mathrm{Liu} \mathrm{Y.} \mathrm{Identifying} \mathrm{microRNA} \mathrm{targets}$ in different gene regions. BMC Bioinformatics (2014) 15(Suppl. 7):S4. doi: 10.1186/1471-2105-15-S7-S4

43. Forman JJ, Legesse-Miller A, Coller HA. A search for conserved sequences in coding regions reveals that the let-7 microRNA targets Dicer within its coding sequence. Proc Natl Acad Sci USA. (2008) 105:14879-84. doi: 10.1073/pnas.0803230105

44. Zhang J, Zhou W, Liu Y, Liu T, Li C, Wang L. Oncogenic role of microRNA532-5p in human colorectal cancer via targeting of the $5^{\prime}$ UTR of RUNX3. Oncol Lett. (2018) 15:7215-20. doi: 10.3892/ol.2018.8217

45. Dharap A, Pokrzywa C, Murali S, Pandi G, Vemuganti R. MicroRNA miR324-3p induces promoter-mediated expression of RelA gene. PLoS ONE (2013) 8:e79467. doi: 10.1371/journal.pone.0079467

46. Kawamata T, Tomari Y. Making RISC. Trends Biochem Sci. (2010) 35:368-76. doi: 10.1016/j.tibs.2010.03.009

47. Jo MH, Shin S, Jung SR, Kim E, Song JJ, Hohng S. Human Argonaute 2 Has diverse reaction pathways on Target RNAs. Mol Cell. (2015) 59:117-24. doi: 10.1016/j.molcel.2015.04.027

48. Krützfeldt J, Rajewsky N, Braich R, Rajeev KG, Tuschl T, Manoharan M, et al. Silencing of microRNAs in vivo with 'antagomirs'. Nature (2005) 438:685-9. doi: 10.1038/nature04303

49. Ameres SL, Horwich MD, Hung JH, Xu J, Ghildiyal M, Weng Z, et al. Target RNA-directed trimming and tailing of small silencing RNAs. Science (2010) 328:1534-9. doi: 10.1126/science.1187058

50. Jonas S, Izaurralde E. Towards a molecular understanding of microRNA-mediated gene silencing. Nat Rev Genet. (2015) 16:421-33. doi: $10.1038 / \mathrm{nrg} 3965$

51. Ellwanger DC, Buttner FA, Mewes HW, Stumpflen V. The sufficient minimal set of miRNA seed types. Bioinformatics (2011) 27:1346-50. doi: 10.1093/bioinformatics/btr149

52. Behm-Ansmant I, Rehwinkel J, Doerks T, Stark A, Bork P, Izaurralde E. mRNA degradation by miRNAs and GW182 requires both CCR4:NOT deadenylase and DCP1:DCP2 decapping complexes. Genes Dev. (2006) 20:1885-98. doi: 10.1101/gad.1424106

53. Christie M, Boland A, Huntzinger E, Weichenrieder O, Izaurralde E. Structure of the PAN3 pseudokinase reveals the basis for interactions with the PAN2 deadenylase and the GW182 proteins. Mol Cell. (2013) 51:360-73. doi: 10.1016/j.molcel.2013.07.011

54. Braun JE, Truffault V, Boland A, Huntzinger E, Chang CT, Haas G, et al. A direct interaction between DCP1 and XRN1 couples mRNA decapping to $5^{\prime}$ exonucleolytic degradation. Nat Struct Mol Biol. (2012) 19:1324-31. doi: $10.1038 / \mathrm{nsmb} .2413$

55. Vasudevan S, Steitz JA. AU-rich-element-mediated upregulation of translation by FXR1 and Argonaute 2. Cell (2007) 128:1105-18. doi: 10.1016/j.cell.2007.01.038

56. Truesdell SS, Mortensen RD, Seo M, Schroeder JC, Lee JH, LeTonqueze O, et al. MicroRNA-mediated mRNA translation activation in quiescent cells and oocytes involves recruitment of a nuclear microRNP. Sci Rep. (2012) 2:842. doi: $10.1038 /$ srep00842

57. Bukhari SIA, Truesdell SS, Lee S, Kollu S, Classon A, Boukhali $M$, et al. A specialized mechanism of translation mediated by FXR1a-associated microRNP in cellular quiescence. Mol Cell. (2016) 61:760-73. doi: 10.1016/j.molcel.2016. 02.013

58. Orom UA, Nielsen FC, Lund AH. MicroRNA-10a binds the $5^{\prime}$ UTR of ribosomal protein mRNAs and enhances their translation. Mol Cell. (2008) 30:460-71. doi: 10.1016/j.molcel.2008.05.001

59. Nishi K, Nishi A, Nagasawa T, Ui-Tei K. Human TNRC6A is an Argonautenavigator protein for microRNA-mediated gene silencing in the nucleus. RNA (2013) 19:17-35. doi: 10.1261/rna.034769.112

60. Benhamed M, Herbig U, Ye T, Dejean A, Bischof O. Senescence is an endogenous trigger for microRNA-directed transcriptional gene silencing in human cells. Nat Cell Biol. (2012) 14:266-75. doi: 10.1038/ncb2443

61. Pitchiaya S, Heinicke LA, Park JI, Cameron EL, Walter NG. Resolving subcellular miRNA trafficking and turnover at single-molecule resolution. Cell Rep. (2017) 19:630-42. doi: 10.1016/j.celrep.2017.03.075

62. Cernilogar FM, Onorati MC, Kothe GO, Burroughs AM, Parsi KM, Breiling A, et al. Chromatin-associated RNA interference components contribute to transcriptional regulation in Drosophila. Nature (2011) 480:391-5. doi: 10.1038/nature10492

63. Bottini S, Hamouda-Tekaya N, Mategot R, Zaragosi LE, Audebert S, Pisano $\mathrm{S}$, et al. Post-transcriptional gene silencing mediated by microRNAs is controlled by nucleoplasmic Sfpq. Nat Commun. (2017) 8:1189. doi: 10.1038/s41467-017-01126-x

64. Allo M, Agirre E, Bessonov S, Bertucci P, Gomez Acuna L, Buggiano V, et al. Argonaute- 1 binds transcriptional enhancers and controls constitutive and alternative splicing in human cells. Proc Natl Acad Sci USA. (2014) 111:15622-9. doi: 10.1073/pnas.1416858111

65. Havens MA, Reich AA, Hastings ML. Drosha promotes splicing of a pre-microRNA-like alternative exon. PLoS Genet. (2014) 10:e1004312. doi: 10.1371/journal.pgen.1004312

66. Miao L, Yao $\mathrm{H}$, $\mathrm{Li} \mathrm{C}, \mathrm{Pu} \mathrm{M}$, Yao $\mathrm{X}$, Yang $\mathrm{H}$, et al. A dual inhibition: microRNA-552 suppresses both transcription and translation of cytochrome P450 2E1. Biochim Biophys Acta (2016) 1859:650-62. doi: 10.1016/j.bbagrm.2016.02.016

67. Xiao M, Li J, Li W, Wang Y, Wu F, Xi Y, et al. MicroRNAs activate gene transcription epigenetically as an enhancer trigger. RNA Biol. (2017) 14:1326-34. doi: 10.1080/15476286.2015.1112487

68. Nam JW, Rissland OS, Koppstein D, Abreu-Goodger C, Jan CH, Agarwal V, et al. Global analyses of the effect of different cellular contexts on microRNA targeting. Mol Cell. (2014) 53:1031-43. doi: 10.1016/j.molcel.2014.02.013

69. Blazie SM, Geissel HC, Wilky H, Joshi R, Newbern J, Mangone M. Alternative polyadenylation directs tissue-specific miRNA targeting in Caenorhabditis elegans Somatic Tissues. Genetics (2017) 206:757-74. doi: 10.1534/genetics.116.196774

70. Barman B, Bhattacharyya SN. mRNA targeting to endoplasmic reticulum precedes ago protein interaction and microRNA (miRNA)-mediated translation repression in mammalian cells. J Biol Chem. (2015) 290:24650-6. doi: 10.1074/jbc.C115.661868

71. Nishi K, Takahashi T, Suzawa M, Miyakawa T, Nagasawa T, Ming Y, et al. Control of the localization and function of a miRNA silencing component TNRC6A by Argonaute protein. Nucleic Acids Res (2015) 43:9856-73. doi: $10.1093 /$ nar/gkv1026 
72. Detzer A, Engel C, Wunsche W, Sczakiel G. Cell stress is related to re-localization of Argonaute 2 and to decreased RNA interference in human cells. Nucleic Acids Res. (2011) 39:2727-41. doi: 10.1093/nar/ gkq1216

73. Bose M, Barman B, Goswami A, Bhattacharyya SN. Spatiotemporal uncoupling of MicroRNA-mediated translational repression and target RNA degradation controls microRNP recycling in mammalian cells. Mol Cell Biol. (2017) 37:e00464-16. doi: 10.1128/MCB.00464-16

74. Gibbings DJ, Ciaudo C, Erhardt M, Voinnet O. Multivesicular bodies associate with components of miRNA effector complexes and modulate miRNA activity. Nat Cell Biol. (2009) 11:1143-9. doi: 10.1038/ncb1929

75. Barrey E, Saint-Auret G, Bonnamy B, Damas D, Boyer O, Gidrol X. PremicroRNA and mature microRNA in human mitochondria. PLOS ONE (2011) 6:e20220. doi: 10.1371/journal.pone.0020220

76. Zhang X, Zuo X, Yang B, Li Z, Xue Y, Zhou Y, et al. MicroRNA directly enhances mitochondrial translation during muscle differentiation. Cell (2014) 158:607-19. doi: 10.1016/j.cell.2014.05.047

77. Gagnon KT, Li L, Chu Y, Janowski BA, Corey DR. RNAi factors are present and active in human cell nuclei. Cell Rep. (2014) 6:211-21. doi: 10.1016/j.celrep.2013.12.013

78. Liu J, Valencia-Sanchez MA, Hannon GJ, Parker R. MicroRNA-dependent localization of targeted mRNAs to mammalian P-bodies. Nat Cell Biol. (2005) 7:719-23. doi: $10.1038 / \mathrm{ncb} 1274$

79. Parker R, Sheth U. P bodies and the control of mRNA translation and degradation. Mol Cell. (2007) 25:635-46. doi: 10.1016/j.molcel.2007.02.011

80. Eulalio A, Behm-Ansmant I, Schweizer D, Izaurralde E. P-body formation is a consequence, not the cause, of RNA-mediated gene silencing. Mol Cell Biol. (2007) 27:3970-81. doi: 10.1128/MCB.00128-07

81. Rajgor D, Mellad JA, Soong D, Rattner JB, Fritzler MJ, Shanahan CM. Mammalian microtubule P-body dynamics are mediated by nesprin-1. J Cell Biol. (2014) 205:457-75. doi: 10.1083/jcb.201306076

82. Carbonaro M, O’Brate A, Giannakakou P. Microtubule disruption targets HIF-1alpha mRNA to cytoplasmic P-bodies for translational repression. J Cell Biol. (2011) 192:83-99. doi: 10.1083/jcb.201004145

83. Pillai RS, Bhattacharyya SN, Artus CG, Zoller T, Cougot N, Basyuk E, et al. Inhibition of translational initiation by Let-7 MicroRNA in human cells. Science (2005) 309:1573-6. doi: 10.1126/science.1115079

84. Molotski N, Soen Y. Differential association of microRNAs with polysomes reflects distinct strengths of interactions with their mRNA targets. RNA (2012) 18:1612-23. doi: 10.1261/rna.033142.112

85. Wee LM, Flores-Jasso CF, Salomon WE, Zamore PD. Argonaute divides its RNA guide into domains with distinct functions and RNA-binding properties. Cell (2012) 151:1055-67. doi: 10.1016/j.cell.2012.10.036

86. Lai X, Wolkenhauer O, Vera J. Understanding microRNA-mediated gene regulatory networks through mathematical modelling. Nucleic Acids Res. (2016) 44:6019-35. doi: 10.1093/nar/gkw550

87. Zhang JF, Fu WM, He ML, Xie WD, Lv Q, Wan G, et al. MiRNA20a promotes osteogenic differentiation of human mesenchymal stem cells by co-regulating BMP signaling. RNA Biol. (2011) 8:829-38. doi: $10.4161 /$ rna.8.5.16043

88. Shu J, Silva B, Gao T, Xu Z, Cui J. Dynamic and modularized microRNA regulation and its implication in human cancers. Sci Rep. (2017) 7:13356. doi: 10.1038/s41598-017-13470-5

89. Siciliano V, Garzilli I, Fracassi C, Criscuolo S, Ventre S, di Bernardo D. MiRNAs confer phenotypic robustness to gene networks by suppressing biological noise. Nat Commun. (2013) 4:2364. doi: 10.1038/ncomms3364

90. Schmiedel JM, Klemm SL, Zheng Y, Sahay A, Blüthgen N, Marks DS, et al. MicroRNA control of protein expression noise. Science (2015) 348:12832. doi: $10.1126 /$ science.aaa1738

91. Ebert MS, Sharp PA. Roles for microRNAs in conferring robustness to biological processes. Cell (2012) 149:515-24. doi: 10.1016/j.cell.2012.04.005

92. Lalanne JB, Taggart JC, Guo MS, Herzel L, Schieler A, Li GW. Evolutionary convergence of pathway-specific enzyme expression stoichiometry. Cell (2018) 173:749-761. doi: 10.1016/j.cell.2018.03.007

93. Schwanhäusser B, Busse D, Li N, Dittmar G, Schuchhardt J, Wolf J, et al. Global quantification of mammalian gene expression control. Nature (2011) 473:337-42. doi: 10.1038/nature10098
94. Denzler R, McGeary SE, Title AC, Agarwal V, Bartel DP, Stoffel M. Impact of MicroRNA levels, target-site complementarity, and cooperativity on competing endogenous RNA-regulated gene expression. Mol Cell (2016) 64:565-79. doi: 10.1016/j.molcel.2016.09.027

95. Kartha RV, Subramanian S. Competing endogenous RNAs (ceRNAs): new entrants to the intricacies of gene regulation. Front Genet. (2014) 5:8. doi: $10.3389 /$ fgene. 2014.00008

96. Barrett SP, Salzman J. Circular RNAs: analysis, expression and potential functions. Development (2016) 143:1838-47. doi: 10.1242/dev.128074

97. Yu CY, Li TC, Wu YY, Yeh CH, Chiang W, Chuang CY, et al. The circular RNA circBIRC6 participates in the molecular circuitry controlling human pluripotency. Nat Commun. (2017) 8:1149. doi: 10.1038/s41467-017-01216-w

98. Sambandan S, Akbalik G, Kochen L, Rinne J, Kahlstatt J, Glock C, et al. Activity-dependent spatially localized miRNA maturation in neuronal dendrites. Science (2017) 355:634-7. doi: 10.1126/science.aaf8995

99. Chou CH, Shrestha S, Yang CD, Chang NW, Lin YL, Liao KW, et al. miRTarBase update 2018: a resource for experimentally validated microRNA-target interactions. Nucleic Acids Res. (2018) 46:D296-D302. doi: $10.1093 / \mathrm{nar} / \mathrm{gkx} 1067$

100. Elkayam E, Faehnle CR, Morales M, Sun J, Li H, Joshua-Tor L. Multivalent recruitment of human argonaute by GW182. Mol Cell. (2017) 67:646-658.e3. doi: 10.1016/j.molcel.2017.07.007

101. Li Y, Liang C, Wong KC, Luo J, Zhang Z. Mirsynergy: detecting synergistic miRNA regulatory modules by overlapping neighbourhood expansion. Bioinformatics (2014) 30:2627-35. doi: 10.1093/bioinformatics/btu373

102. Lemus-Diaz N, Boker KO, Rodriguez-Polo I, Mitter M, Preis J, Arlt M, et al. Dissecting miRNA gene repression on single cell level with an advanced fluorescent reporter system. Sci Rep. (2017) 7:45197. doi: 10.1038/srep45197

103. Bose M, Bhattacharyya SN. Target-dependent biogenesis of cognate microRNAs in human cells. Nat Commun. (2016) 7:12200. doi: $10.1038 /$ ncomms 12200

104. Pons-Espinal M, de Luca E, Marzi MJ, Beckervordersandforth R, Armirotti A, Nicassio F, et al. Synergic functions of miRNAs determine neuronal fate of adult neural stem cells. Stem Cell Rep. (2017) 8:1046-61. doi: 10.1016/j.stemcr.2017.02.012

105. Sahu M, Mallick B. Deciphering synergistic regulatory networks of microRNAs in hESCs and fibroblasts. Int J Biol Macromol. (2018) 113:127986. doi: 10.1016/j.ijbiomac.2018.03.061

106. Abbas T, Dutta A. p21 in cancer: intricate networks and multiple activities. Nat Rev Cancer (2009) 9:400-14. doi: 10.1038/nrc2657

107. Wu S, Huang S, Ding J, Zhao Y, Liang L, Liu T, et al. Multiple microRNAs modulate p21Cip1/Wafl expression by directly targeting its $3^{\prime}$ untranslated region. Oncogene (2010) 29:2302-8. doi: 10.1038/onc.2010.34

108. Yao W, Guo G, Zhang Q, Fan L, Wu N, Bo Y. The application of multiple miRNA response elements enables oncolytic adenoviruses to possess specificity to glioma cells. Virology (2014). 458-459, 69-82. doi: 10.1016/j.virol.2014.04.007

109. Kucherenko MM, Shcherbata HR. miRNA targeting and alternative splicing in the stress response - events hosted by membrane-less compartments. J Cell Sci. (2018) 131:jcs202002. doi: 10.1242/jcs.202002

110. Wang K, Zhang S, Weber J, Baxter D, Galas DJ. Export of microRNAs and microRNA-protective protein by mammalian cells. Nucleic Acids Res. (2010) 38:7248-59. doi: 10.1093/nar/gkq601

111. Leung AK, Calabrese JM, Sharp PA. Quantitative analysis of Argonaute protein reveals microRNA-dependent localization to stress granules. Proc Natl Acad Sci USA. (2006) 103:18125-30. doi: 10.1073/pnas.0608845103

112. Protter DS, Parker R. Principles and Properties of Stress Granules. Trends Cell Biol. (2016) 26:668-79. doi: 10.1016/j.tcb.2016.05.004

113. Roderburg C, Luedde T. Circulating microRNAs as markers of liver inflammation, fibrosis and cancer. J Hepatol. (2014) 61:1434-7. doi: 10.1016/j.jhep.2014.07.017

114. Sohn W, Kim J, Kang SH, Yang SR, Cho JY, Cho HC, et al. Serum exosomal microRNAs as novel biomarkers for hepatocellular carcinoma. Exp Mol Med. (2015) 47:e184. doi: 10.1038/emm.2015.68

115. Pereira-da-Silva T, Coutinho Cruz M, Carrusca C, Cruz Ferreira R, Napoleao P, Mota Carmo M. Circulating microRNA profiles in different arterial 
territories of stable atherosclerotic disease: a systematic review. Am J Cardiovasc Dis. (2018) 8:1-13.

116. Iftikhar $\mathrm{H}$, Carney GE. Evidence and potential in vivo functions for biofluid miRNAs: from expression profiling to functional testing: potential roles of extracellular miRNAs as indicators of physiological change and as agents of intercellular information exchange. Bioessays (2016) 38:367-78. doi: 10.1002/bies.201500130

117. Chen X, Ba Y, Ma L, Cai X, Yin Y, Wang K, et al. Characterization of microRNAs in serum: a novel class of biomarkers for diagnosis of cancer and other diseases. Cell Res (2008) 18:997-1006. doi: 10.1038/cr.2008.282

118. Arroyo JD, Chevillet JR, Kroh EM, Ruf IK, Pritchard CC, Gibson DF, et al. Argonaute2 complexes carry a population of circulating microRNAs independent of vesicles in human plasma. Proc Natl Acad Sci USA (2011) 108:5003-8. doi: 10.1073/pnas.1019055108

119. Cogswell JP, Ward J, Taylor IA, Waters M, Shi Y, Cannon B, et al. Identification of miRNA changes in Alzheimer's disease brain and CSF yields putative biomarkers and insights into disease pathways. J Alzheimers Dis. (2008) 14:27-41. doi: 10.3233/JAD-2008-14103

120. Gallo A, Tandon M, Alevizos I, Illei GG. The majority of microRNAs detectable in serum and saliva is concentrated in exosomes. PLoS ONE (2012) 7:e30679. doi: 10.1371/journal.pone.0030679

121. Zhou Q, Li M, Wang X, Li Q, Wang T, Zhu Q, et al. Immune-related microRNAs are abundant in breast milk exosomes. Int J Biol Sci (2012) 8:118-23. doi: 10.7150/ijbs.8.118

122. Weber JA, Baxter DH, Zhang S, Huang DY, Huang KH, Lee MJ, et al. The microRNA spectrum in 12 body fluids. Clin Chem. (2010) 56:1733-41. doi: $10.1373 /$ clinchem.2010.147405

123. da Silveira JC, Veeramachaneni DN, Winger QA, Carnevale EM, Bouma GJ. Cell-secreted vesicles in equine ovarian follicular fluid contain miRNAs and proteins: a possible new form of cell communication within the ovarian follicle. Biol Reprod. (2012) 86:71. doi: 10.1095/biolreprod.111.093252

124. Mitchell PS, Parkin RK, Kroh EM, Fritz BR, Wyman SK, PogosovaAgadjanyan EL, et al. Circulating microRNAs as stable blood-based markers for cancer detection. Proc Natl Acad Sci USA. (2008) 105:10513-8. doi: 10.1073/pnas.0804549105

125. Turchinovich A, Weiz L, Langheinz A, Burwinkel B. Characterization of extracellular circulating microRNA. Nucleic Acids Res. (2011) 39:7223-33. doi: $10.1093 /$ nar/gkr254

126. Vickers KC, Palmisano BT, Shoucri BM, Shamburek RD, Remaley AT. MicroRNAs are transported in plasma and delivered to recipient cells by high-density lipoproteins. Nat Cell Biol. (2011) 13:423-33. doi: $10.1038 /$ ncb2210

127. Tabet F, Vickers KC, Cuesta Torres LF, Wiese CB, Shoucri BM, Lambert G, et al. HDL-transferred microRNA-223 regulates ICAM-1 expression in endothelial cells. Nat Commun. (2014) 5:3292. doi: 10.1038/ncomms4292

128. Turchinovich A, Weiz L, Burwinkel B. Extracellular miRNAs: the mystery of their origin and function. Trends Biochem Sci. (2012) 37:460-5. doi: 10.1016/j.tibs.2012.08.003

129. Kosaka N, Iguchi H, Yoshioka Y, Takeshita F, Matsuki Y, Ochiya T. Secretory mechanisms and intercellular transfer of microRNAs in living cells. $J$ Biol Chem. (2010) 285:17442-52. doi: 10.1074/jbc.M110.107821

130. Zhu JJ, Liu YF, Zhang YP, Zhao CR, Yao WJ, Li YS, et al. VAMP3 and SNAP23 mediate the disturbed flow-induced endothelial microRNA secretion and smooth muscle hyperplasia. Proc Natl Acad Sci USA. (2017) 114:8271-6. doi: 10.1073/pnas.1700561114

131. Gumurdu A, Yildiz R, Eren E, Karakulah G, Unver T, Genc S, et al. MicroRNA exocytosis by large dense-core vesicle fusion. Sci Rep. (2017) 7:45661. doi: 10.1038/srep45661
132. Yang M, Chen J, Su F, Yu B, Su F, Lin L, et al. Microvesicles secreted by macrophages shuttle invasion-potentiating microRNAs into breast cancer cells. Mol Cancer (2011) 10:117. doi: 10.1186/1476-4598-10-117

133. Hannafon BN, Carpenter KJ, Berry WL, Janknecht R, Dooley WC, Ding WQ. Exosome-mediated microRNA signaling from breast cancer cells is altered by the anti-angiogenesis agent docosahexaenoic acid (DHA). Mol Cancer (2015) 14:133. doi: 10.1186/s12943-015-0400-7

134. Zhou W, Fong MY, Min Y, Somlo G, Liu L, Palomares MR, et al. Cancer-secreted miR-105 destroys vascular endothelial barriers to promote metastasis. Cancer Cell (2014) 25:501-15. doi: 10.1016/j.ccr.2014.03.007

135. Hu Y, Rao SS, Wang ZX, Cao J, Tan YJ, Luo J, et al. Exosomes from human umbilical cord blood accelerate cutaneous wound healing through miR-21-3p-mediated promotion of angiogenesis and fibroblast function. Theranostics (2018) 8:169-84. doi: 10.7150/thno.21234

136. Sakha S, Muramatsu T, Ueda K, Inazawa J. Exosomal microRNA miR1246 induces cell motility and invasion through the regulation of DENND2D in oral squamous cell carcinoma. Sci Rep. (2016) 6:38750. doi: $10.1038 /$ srep38750

137. Fabbri M. MicroRNAs and miRceptors: a new mechanism of action for intercellular communication. Philos Trans R Soc Lond B Biol Sci. (2018) 373:E2110-6. doi: 10.1098/rstb.2016.0486

138. Fabbri M, Paone A, Calore F, Galli R, Gaudio E, Santhanam R, et al. MicroRNAs bind to Toll-like receptors to induce prometastatic inflammatory response. Proc Natl Acad Sci USA. (2012) 109:E2110-E2116. doi: 10.1073/pnas.1209414109

139. Lehmann SM, Kruger C, Park B, Derkow K, Rosenberger K, Baumgart $\mathrm{J}$, et al. An unconventional role for miRNA: let-7 activates Toll-like receptor 7 and causes neurodegeneration. Nat Neurosci. (2012) 15:827-35. doi: $10.1038 / \mathrm{nn} .3113$

140. Chen X, Liang H, Zhang J, Zen K, Zhang CY. Secreted microRNAs: a new form of intercellular communication. Trends Cell Biol. (2012) 22:125-32. doi: 10.1016/j.tcb.2011.12.001

141. Xu J, Chen Q, Zen K, Zhang C, Zhang Q. Synaptosomes secrete and uptake functionally active microRNAs via exocytosis and endocytosis pathways. J Neurochem. (2013) 124:15-25. doi: 10.1111/jnc.12057

142. Tian T, Zhu YL, Zhou YY, Liang GF, Wang YY, Hu FH, et al. Exosome uptake through clathrin-mediated endocytosis and macropinocytosis and mediating miR-21 delivery. J Biol Chem. (2014) 289:22258-67. doi: 10.1074/jbc.M114.588046

143. Wei F, Ma C, Zhou T, Dong X, Luo Q, Geng L, et al. Exosomes derived from gemcitabine-resistant cells transfer malignant phenotypic traits via delivery of miRNA-222-3p. Mol Cancer (2017) 16:132. doi: 10.1186/s12943-017-0694-8

144. Aucher A, Rudnicka D, Davis DM. MicroRNAs transfer from human macrophages to hepato-carcinoma cells and inhibit proliferation. J Immunol. (2013) 191:6250-60. doi: 10.4049/jimmunol.1301728

Conflict of Interest Statement: The authors declare that the research was conducted in the absence of any commercial or financial relationships that could be construed as a potential conflict of interest.

Copyright (C) 2018 O'Brien, Hayder, Zayed and Peng. This is an open-access article distributed under the terms of the Creative Commons Attribution License (CC BY). The use, distribution or reproduction in other forums is permitted, provided the original author(s) and the copyright owner(s) are credited and that the original publication in this journal is cited, in accordance with accepted academic practice. No use, distribution or reproduction is permitted which does not comply with these terms. 